\title{
Trends in Urban Immunization Coverage in India: A Meta-Analysis and Meta-Regression
}

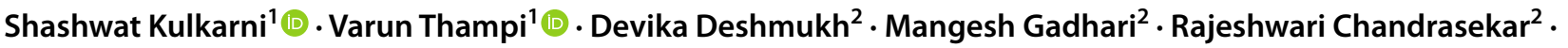 \\ Mrudula Phadke ${ }^{3}$ (1)
}

Received: 27 October 2020 / Accepted: 4 June 2021 / Published online: 16 September 2021

(c) Dr. K C Chaudhuri Foundation 2021

\begin{abstract}
Objectives To assess the gaps and trends in child immunization coverage among urban and rural areas in India, and compare the success of immunisation program in each.

Methods PubMed, Scopus, and Crossref, and Google Scholar electronic databases were searched on October 9, 2019, and March 21, 2020, for studies that measured and reported immunization coverage indicators in India. Random-effects metaanalyses and meta-regressions were conducted.

Results The authors' search identified 545 studies, and 2 were obtained by expert suggestion. Among these 68 studies and 6 surveys were included. They found that full immunization coverage has grown yearly at $2.65 \%$ and $0.82 \%$ in rural and urban areas, respectively whereas partial immunization coverage declined by $-2.44 \%$ and $-0.69 \%$, respectively. Percentage of nonimmunized children did not show a statistically significant trend in either.

Conclusion While rural immunization coverage has seen a large increase over the past two decades, the progress in urban areas is weak and negligible. This was largely attributable to a focus on minimizing dropouts in rural areas. However, a lack of significant reduction in unimmunized children may indicate left-out children or pockets in both rural and urban areas. The poor performance of immunization programs in urban areas, coupled with a larger impact of COVID-19, warrants that India urgently adopts urban-sensitive and urban-focused policies and programs.
\end{abstract}

Keywords Urban immunization $\cdot$ Rural immunization $\cdot$ Immunization coverage $\cdot$ Immunization programme $\cdot$ Immunization trends

\section{Introduction}

As the nation's health system battles the COVID-19 pandemic, a diversion of resources $[1,2]$ along with temporary suspension of vaccination outreach sessions [3, 4] makes the ominous threat of vaccine-preventable diseases (VPDs) more palpable. In addition to this, India already falls short in achieving universal immunization by a significant margin

Shashwat Kulkarni

mail@shashwatk.com

1 RJMC Health and Nutrition Mission, Department of Women and Child Development, Government of Maharashtra, Mumbai, India

2 UNICEF Office for Maharashtra, Mumbai, Maharashtra, India

3 Public Health Department, Government of Maharashtra, UNICEF Office for Maharashtra, Maharashtra University of Health Sciences, Mumbai, Maharashtra, India
[5], as indicated by the results of the National Family Health Survery-4 (NFHS-4) [6], that reveal 38\% of children may not be fully immunized. Urban immunization coverage is often cited as a key bottleneck to achieving this universal coverage [7], as pockets of squatter settlements and expanding peri-urban zones are often densely populated and have few public services, including health care, thereby increasing the risk of VPD outbreaks [8]. The unique nature of urban areas, hence, makes them a distinct paradigm while formulating, implementing, and evaluating immunization policies.

However, with multiple surveys and studies reporting different coverage results, policymakers have often expressed the need for a singular reference, in order to better study the disparity of immunization programs in urban and rural areas. In this paper, along with arriving at robust estimates of the true value of immunization coverage over time for both rural and urban areas, the authors also explore causes of disparity. Thus, the results of the present study can aid policymakers in 
creating appropriate strategies to achieve universal immunization coverage, in light of the COVID-19 pandemic.

\section{Materials and Methods}

First, literature search was conducted using a predefined inclusion-exclusion criteria for localized studies, and expert recommendations for national surveys. Once the data were collected and compiled, a meta-regression was conducted to assess the trends in immunization coverage in a robust manner. To further isolate and understand the factors leading to the intriguing trends observed, a meta-analysis was conducted for immunization coverage measured between 2005 and 2015, and after 2015 that were performed separately for urban and rural areas. The year 2015 was chosen as a reference point, to study the effect of policy reorientation around immunization, specifically Mission Indradhanush, as well as the policy impact of publication of the NFHS-4.

\section{Localized Studies on Coverage}

Four databases-PubMed, Scopus, and CrossRef, and Google Scholar were queried on 9th October 2019, and subsequently on 21st March 2020 for studies in the past two decades (2000-2020). The keywords used are described in Table 1. After removing duplicates, it yielded a total of 545 studies. Two studies that were not found in the search were included from expert recommendations. The abstracts of all these studies were scanned for suitability according to a predefined inclusion-exclusion criterion.

\section{Selection Criteria}

The authors included studies that provided numerical estimates for immunization coverages, and only studies that reported sample size or standard errors were considered. Further, it was also ensured that studies conducted in India were only included. For studies that were community-based rather than being population-based, it was ensured that the cohort of the study was representative of a larger population within that geopolitical zone. Subsequently, the authors included studies that measured the coverages in a specific

Table 1 Search criteria

\begin{tabular}{ll}
\hline$\#$ & Searches \\
\hline 1 & India \\
2 & Urban \\
3 & Child/or Children \\
4 & Immunization/or Immunised \\
5 & Vaccine/or Vaccination \\
6 & Coverage \\
\hline
\end{tabular}

group (such as children of migrant workers) only if a comparison with the general population was measured. They included only the baselines of RCTs and intervention-based studies.

As this analysis pertains to the administrative and programmatic aspects of childhood immunization, the authors allowed flexibility in the definition of 'Full Immunization,' to suit the local norms. There were very few deviations from the WHO EPI and the National definition of (i) one dose of BCG, (ii) three doses each of oral polio vaccine (OPV), diphtheria, pertussis and tetanus (DPT) and hepatitis B vaccines (HBV), and (iii) one dose of measles (or MMR) before the age of one year. Only the coverage estimates for children who were 12-24 mo old and received these vaccinations within the first 12 mo were analyzed and are presented.

For the verification of immunization, both studies that used recall and immunization cards were included. In the case where a study provided both, the combined estimate was chosen. A child who did not complete full immunization was termed as 'partially immunized,' and estimates of children who did not receive any vaccines were also extracted. Estimates for the coverage of any of the individual vaccines were also extracted.

Qualitative Studies or editorial, review article, or metaanalysis were excluded. Along with this, studies that did not pertain to the coverage of immunization or covered a nonrepresentative group were also excluded.

The list of all studies included in the analysis is presented in the Supplementary Table S1.

\section{Nationwide Surveys}

The present analysis also included surveys that were performed over the past two decades, obtained through literature search and expert recommendation.

The list of all studies included in the analysis is presented in the Supplementary Table S2.

\section{Model Specification}

All statistical analyses were performed on $\mathrm{R}$ version 3.6.1 using the 'metafor' package. Standard errors were calculated from the reported estimates assuming a binomial distribution.

Random-effects meta-analysis using the DerSimonian and Laird (DL) method was performed and estimates were arrived at. For meta-regression, a mixed-effect model using the DL method was utilized. The results were analyzed, and insightful outcomes are presented and discussed in this paper.

The model specified in the meta-regression was of the form 
$y_{i}=\beta_{0}+\beta_{1} *$ Year $+\epsilon$

Where $y_{i}$ is the reported coverage in a study or survey, $\beta_{0}$ is an intercept, and $\beta_{1}$ indicates the growth or decline of the coverage over Years.

\section{Results}

The search, illustrated in Fig. 1, yielded a total of 545 studies, 2 studies were identified through expert recommendation. After preliminary screening based on abstracts, the full text of 272 studies was obtained. Full text studies were excluded for not pertaining to immunization coverage ( $n$ $=132)$, not reporting sample sizes or standard errors $(n=$ $59)$, and covering a nonrepresentative group $(n=13)$. Six surveys were added using expert recommendations. Metaregressions and meta-analyses were performed for the 74 studies and surveys hence obtained [6,9-79]. The results of these have been presented and discussed in this paper.

\section{Meta-Regression}

To examine the trends in immunization coverage in India, the authors first conducted a meta-regression of the full immunization coverage (FIC) with years as the regressor. This was done separately for urban and rural coverages. The regression is displayed graphically in Fig. 2a. Through this, positive growth in FIC in rural areas at a pace of $2.65 \%$ per year $(p=0.0002)$ was observed. This result is statistically significant at $\alpha=.05$. In urban areas, however, the pace of growth in FIC is $0.82 \%$ per year with a $p$ value of 0.179 . It can, hence, be concluded that urban growth rate is not greater than 0 at any acceptable confidence level.

To further explore trends, another meta-regression was conducted on the partial immunization coverage (PIC) with the year as the regressor (Fig. 2b). The rural PIC showed a decline of $-2.44 \%$ per year $(p=0.001)$, which is statistically significant at $\alpha=.05$. The urban PIC, on the other hand, showed a decline of $-0.69 \%$ per year ( $p$ $=0.244)$. This cannot statistically be shown to be distinct from 0 .

The authors also conducted another meta-regression on children that received no vaccines Fig. 2c). It was found here that nonimmunization has decreased in both rural and urban areas with a decline rate of $-0.81 \%(p=0.124)$ and $-0.04 \%$ $(p=0.895)$ per year, respectively. However, these results are not statistically significant at $\alpha=.05$. Through these analyses, it is concluded that rural immunization coverage in India has significantly improved, and the success comes largely via higher rates of completion of the immunization course. The urban immunization coverage, on the other hand, shows no improvement and has stayed constant over the past one and a half-decade. Interestingly, all three meta-regressions indicate that rural immunization coverage seems to have surpassed urban immunization coverage around the year 2012.

Fig. 1 Search criteria diagram
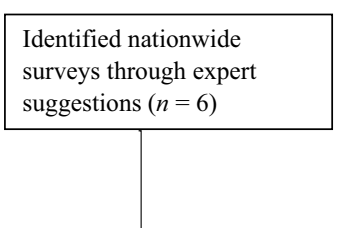

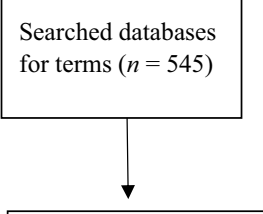

Additional records identified through expert suggestions $(n=2)$

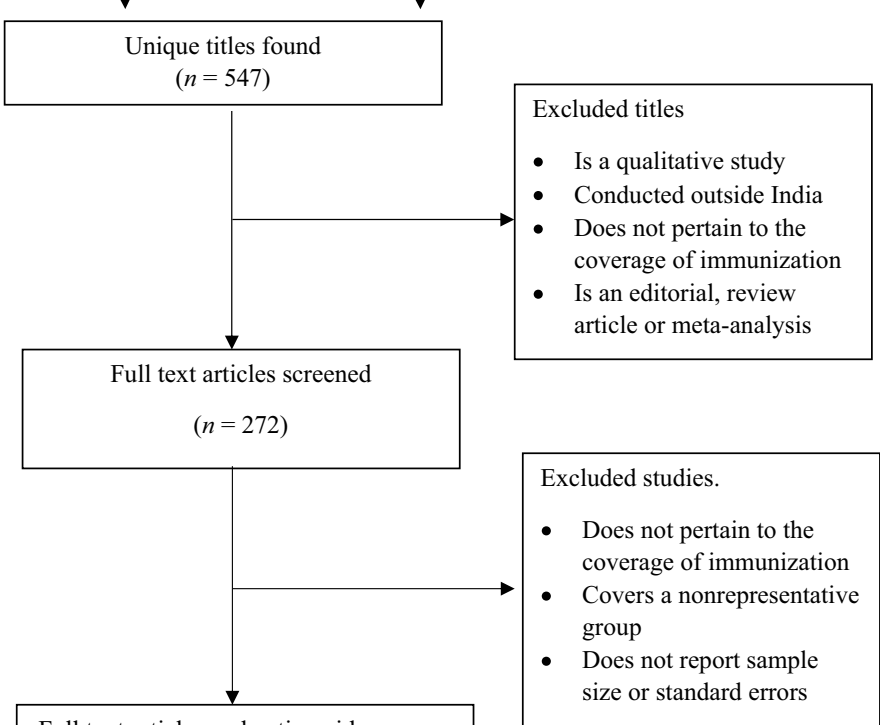

Full text articles and nationwide surveys included in the review $(n=74)$ 
Fig. 2 Results of MetaRegression for (a) Full immunisation coverage, (b) Partial immunisation coverage, (c)

Non-immunisation

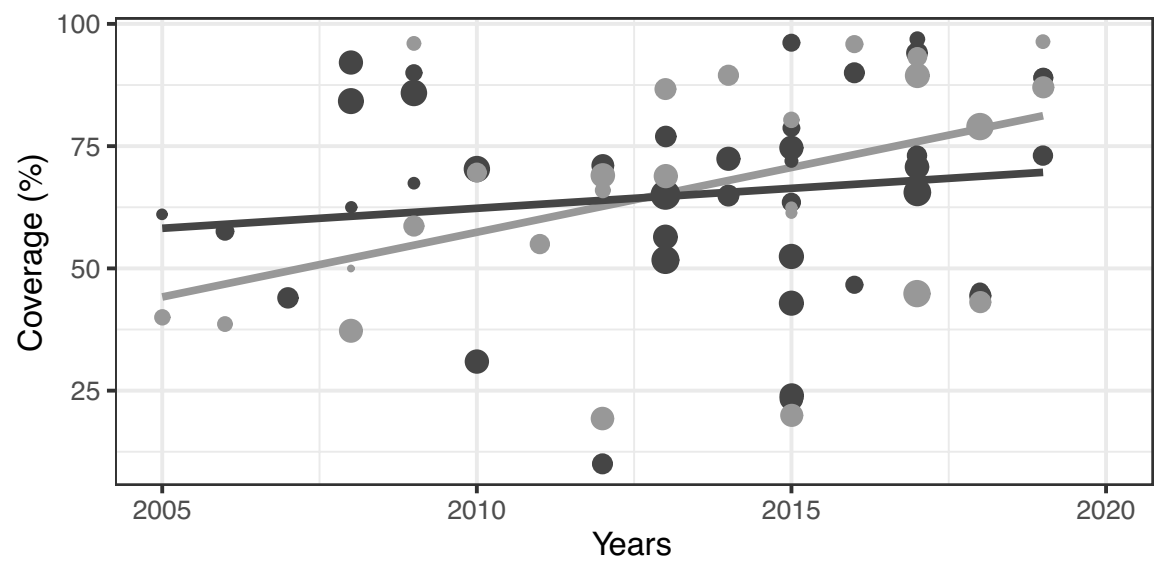

(a)

Meta-Regression of FIC over the years

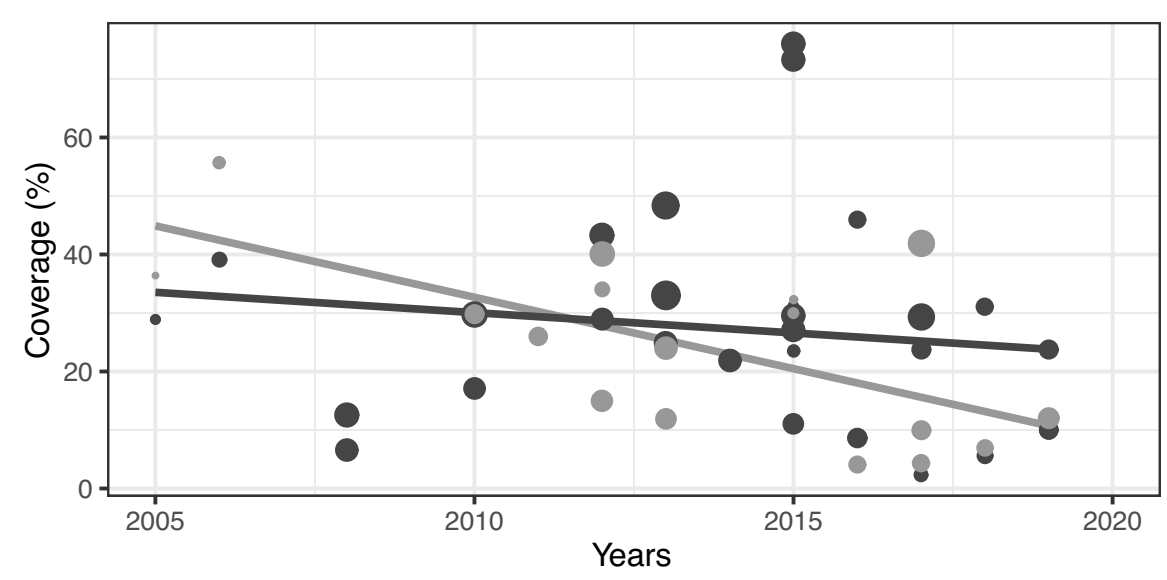

(b)

Meta-Regression of FIC over the years

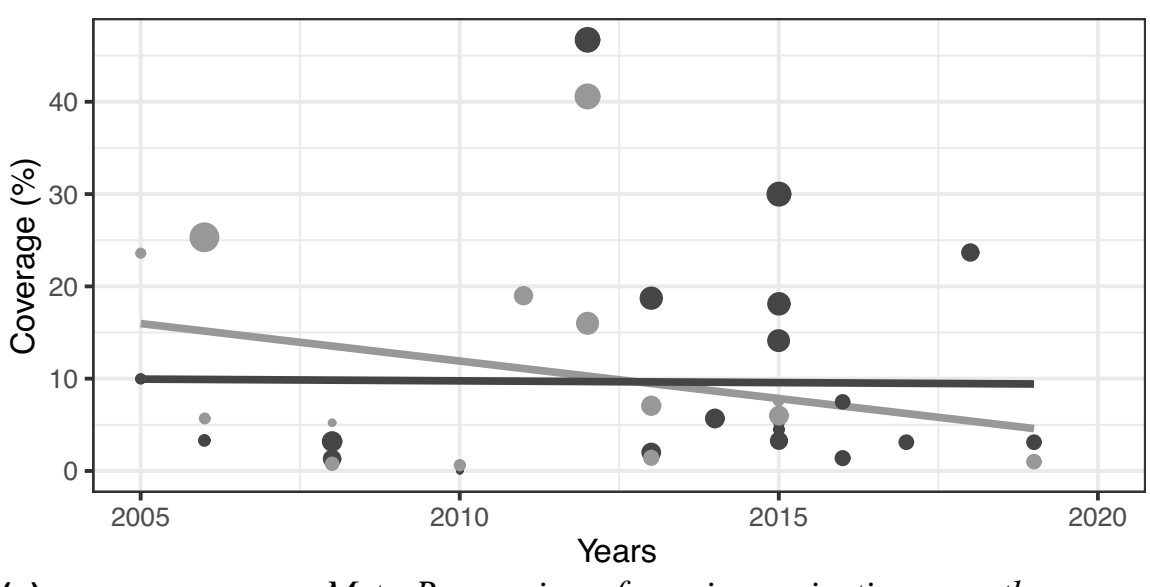

(c)

Meta-Regression of non-immunization over the years.

Points indicate the reported coverage of each indicator;

Size of the points indicate relative weightage of each study or survey in the meta-regression;

Urban coverage is indicated by dark grey points and lines;

Rural coverage is indicated by light grey points and lines. 


\section{Meta-Analysis}

A meta-analysis over two time periods yielded summary effects that reflect a good estimate of the indicator coverage over the given period (presented in Table 2) along with forest plots (presented in Table 3), that aid in further analysis.

In Table 2, the authors present against each immunization indicator the estimated coverage in each period, for both rural and urban areas. They then calculate the difference in the growth in rural vis-à-vis urban coverage between the two periods. They present here only the indicators for which estimates were available for both rural and urban areas over both the periods. Many indicators had no study or survey estimating their coverage.

The meta-analysis helps validate the authors' previous findings by looking at coverages of individual vaccines. For instance, in rural areas, they observe that the increase in coverage of the measles vaccine, which is administered at a much later stage, has increased to equal the coverage of the BCG vaccine, which is administered at birth. Similarly, in urban areas, the coverage of OPV1 vaccine shows a drop, and the coverage of OPV2 vaccine shows a mere increase of $0.9 \%$.

These findings indicate that rural areas have been successful in significantly reducing and nearly eliminating dropouts, further strengthening the authors' previous hypotheses. Urban areas show little to no progress across vaccines in this analysis as well.

Table 2 Summary effects as obtained through meta-analyses

\begin{tabular}{llllrc}
\hline Indicator & Location & $2005-15$ & $2015-20$ & Growth & $\begin{array}{c}\text { Diff. in } \\
\text { growth }\end{array}$ \\
\hline FIC & Rural & 60.4 & 79.9 & 19.5 & 8.7 \\
& Urban & 62.3 & 73.1 & 10.8 & \\
PIC & Rural & 29.9 & 13.1 & -16.8 & -5.8 \\
& Urban & 31.0 & 20.0 & -11.0 & \\
None & Rural & 10.4 & 1.0 & -9.4 & -5.7 \\
& Urban & 10.3 & 6.6 & -3.7 & \\
BCG & Rural & 82.5 & $99.5 *$ & 17.0 & 11.7 \\
& Urban & 81.4 & 86.6 & 5.3 & \\
DPT3 & Rural & 71.5 & 84.0 & 12.5 & 1.7 \\
& Urban & 62.2 & 73.0 & 10.8 & \\
OPV1 & Rural & 79.9 & $99.8^{*}$ & 19.9 & 24.9 \\
& Urban & 84.9 & 79.9 & -4.9 & \\
OPV2 & Rural & 75.9 & $99.3 *$ & 23.4 & 22.4 \\
& Urban & 75.9 & 76.8 & 0.9 & \\
OPV3 & Rural & 70.4 & $99.2^{*}$ & 28.8 & 22.3 \\
& Urban & 67.4 & 73.9 & 6.5 & \\
Measles & Rural & 65.4 & 91.3 & 25.9 & 21.5 \\
& Urban & 63.5 & 67.9 & 4.4 & \\
\hline
\end{tabular}

*Not a summary effect as only a single study was available

\section{Discussion}

India built its immunization infrastructure and capacities starting with its efforts in smallpox elimination [80], which was harnessed by the Expanded Program on Immunization (EPI) in 1978, followed by the Universal Immunization Programme (UIP) in 1985, expanding in 2006 and 2017 [81, 82]. However, vaccination programs in India have historically experienced not only slow acceptance and reluctance but opposition as well [82]. This slow progression in immunization coverage, has prompted the government to make several policy improvements such as the Mission Indradhanush. However, a rigorous quantitative analysis of the outcomes of these programs, and comparison of immunisation progress amongst urban and rural areas was lacking. This is the first time, as far as the authors know, that an evidence-based meta-analysis of immunization coverage has been performed for India.

In the present paper, three main findings are presented, the first being that full immunization coverage in urban areas have shown little to no growth while rural coverage has significantly improved over the past two decades. The second finding is that the dropout rates have declined at a faster rate for rural than for urban areas. The authors' third finding is that neither rural nor urban areas have seen major success in reducing the percentage of unimmunized children.

Through these findings, the authors infer that the improvement in rural immunization coverage over urban can be largely attributed to a focus on minimizing dropouts. However, a lack of reduction in unimmunized children in both rural and urban areas suggests the possiblity of underreached pockets. National policymakers keen on increasing the national immunization coverage would be benefitted through a targeted approach for identifying and reaching children in underserved pockets both for rural and urban areas, as well as enhancing focus on minimizing dropouts in urban slums. To identify underserved pockets and hard to reach areas, states should ensure that areas are demarcated among health facilities and comprehensive headcount surveys and microplans are established and regularly updated. Further, mobile sessions and flexible timings can play a big role in strengthening immunization in these areas. For tracking children, due lists must be regularly prepared and utilized by health workers. A strong communication intervention through advocacy, interpersonal communication and community engagement, thereby creating a cohesive environment for women to take informed decisions related to immunization, would be expected to go a long way in minimizing dropouts in urban slums.

The findings in the present paper verify and corroborate factors postulated in previous literature and provide 
Table 3 Forest plots of the meta-analyses of full immunization coverage (FIC) within two time periods and amongst urban and rural areas

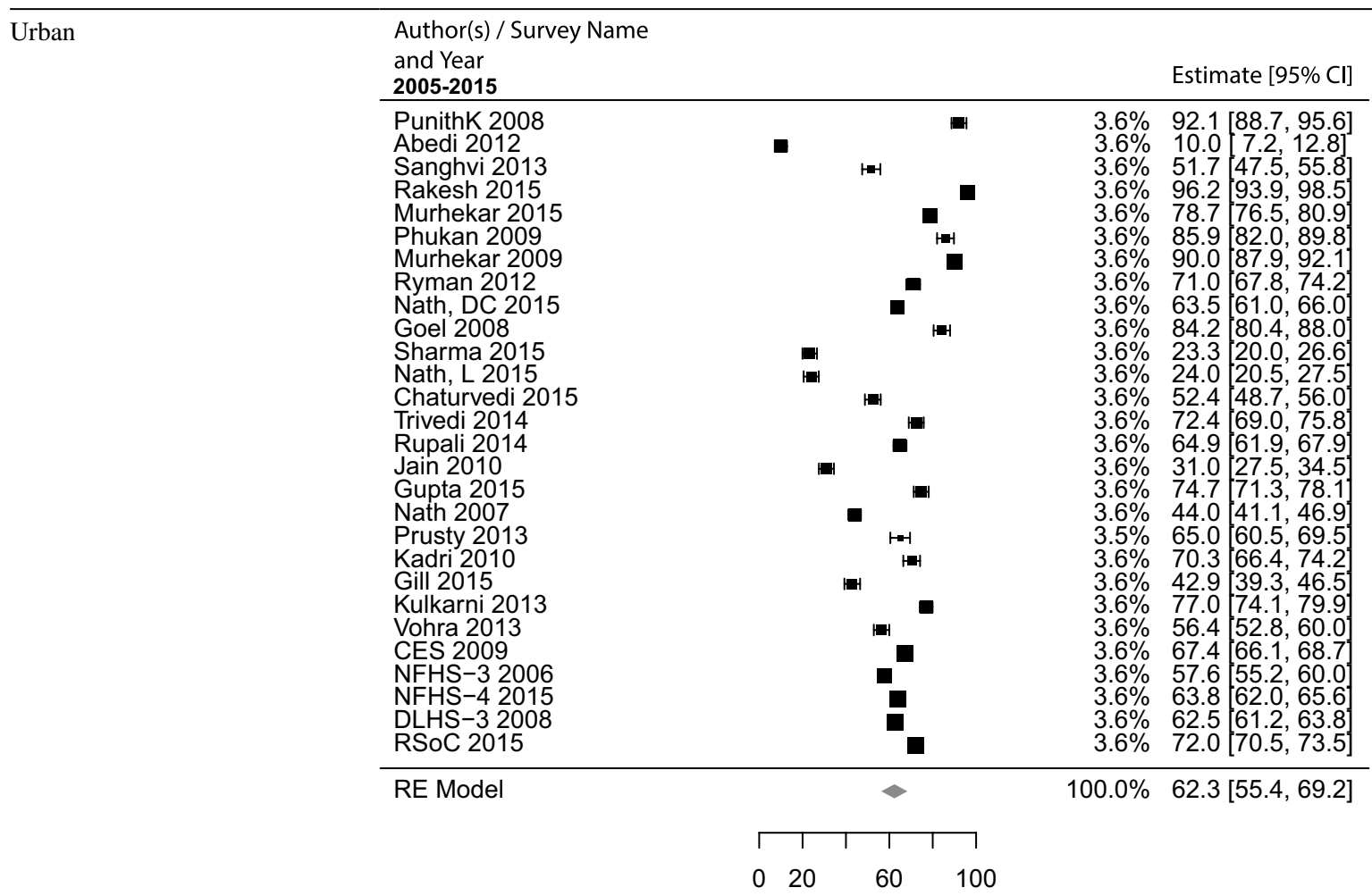

Coverage of Urban 2005 to 2015 FIC (\%)

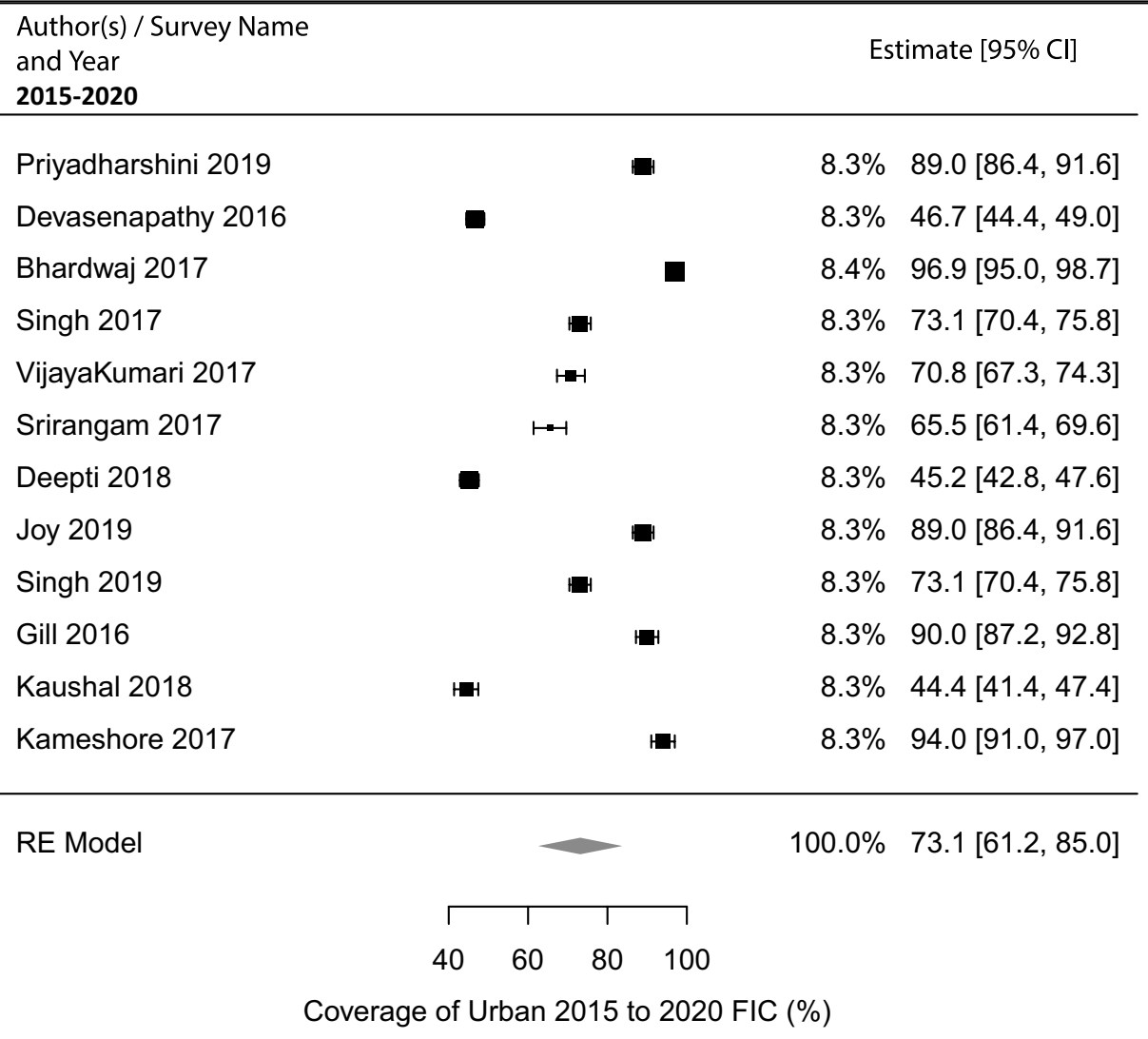


Table 3 (continued)

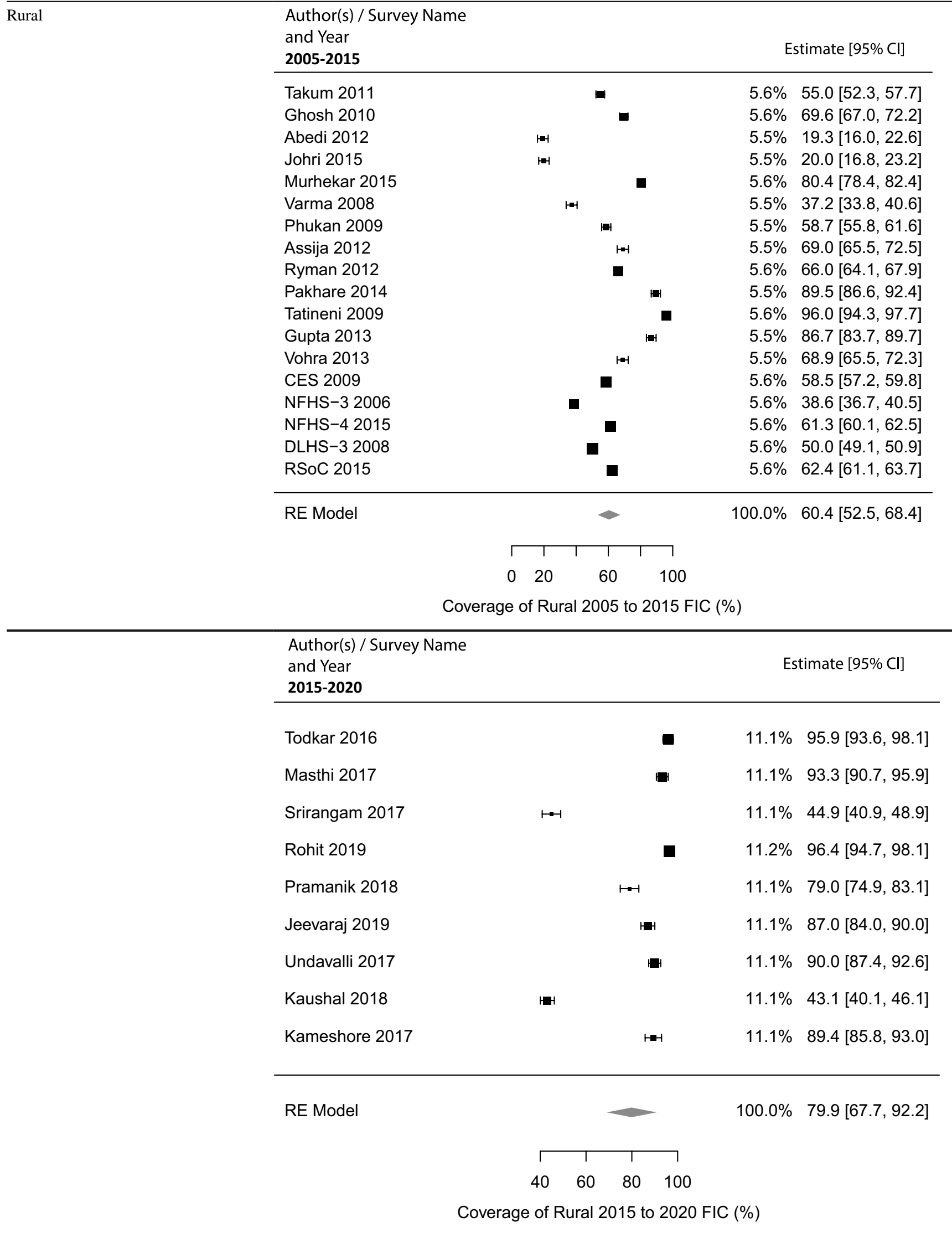


a robust backing for both previous empirical findings as well as highlight the need for urban-oriented policy interventions $[8,83,84]$. This becomes especially critical as immunization services have been disrupted by COVID19 , and lockdown measures have led to a mass exodus of migrant workers to rural areas and smaller towns [85] causing a rapid change in service demand patterns, misplaced/left behind immunization cards and overcrowded villages. When these families return to the slums, there is a high potential for vaccine-preventable disease outbreaks. To compound this, parents would be wary of bringing their children to clinics or outreach immunization sessions, for fear of inadvertently contracting the virus [86].

In addition to the challenges posed by the pandemic, previous literature points out that urban immunization inherently faces two distinct types of issues-supply and demand [87].

The paramount supply-side factor is that urban primary health systems haven't been able to keep pace with the rapidly growing and floating urban population [7], and engagement with medical colleges are minimal and unstructured [88]. Further, as only $40 \%$ of slums are formally recognized by the government [89], lack of access to basic municipal services limits holistic improvements in health outcomes $[90,91]$. These issues are compounded by shortages in posts for health workers [92], lack of supportive supervision [9], and inadequate microplanning, leading to insufficient quantity of vaccines or overcrowded sessions with long wait times [93].

Urban slums present a multitude of demand-side issues. Researchers find that larger families are less likely to be hesitant towards vaccinations [94]. Compared to rural areas, urban areas are less likely to have joint families, and conflicting priorities often leads to missed vaccination appointments. Further, unawareness of the need of immunization and absence of motivation to avail services [10, 11, 83], false belief that a child being sick or underweight is a contraindication for vaccination [11,95], refusal to vaccinate the child over religious beliefs, fear of side effects or perceived safety of the vaccine $[10,96]$ are common issues as a result of poor information circulation in the community.

The insights from this paper can also be extended to adult vaccination programs, which have gained increased importance given the ongoing COVID-19 vaccination program. Interventions to improve adult vaccination coverage can be informed from the success of child immunization programs. These include interventions in raising awareness, mobilizing health systems, building capacities of healthcare workers, and running effective campaigns to reduce vaccine hesitancy. Conversely, COVID-19 vaccination program will help strengthen our immunization programs, especially in urban areas where its success is critical in order to control the pandemic. Subsequently, we can consider integrating and universalizing immunization programs to cover both child and adult vaccinations, and help improve coverage of both, especially in urban areas [97].

Urban areas present significant inequalities, both amongst, and within. The demographic mix across communities also varies significantly within pockets of a city and between them [98]. It is imperative that urban health policies, especially immunization have a multipronged approach, one that harnesses collective community involvement and ownership, as both service delivery and community perception to the service play key roles. Further research is needed to ascertain the magnitude of each of the factors, and to create appropriate policies to address the disparities found in this paper.

\section{Conclusion}

The COVID-19 pandemic threatens us with the reversal of decades of progress in immunization, urban areas being especially susceptible. In the present paper, the authors have attempted to gauge this susceptibility and compare the success of immunization programs between rural and urban areas. They found that rural areas have shown tremendous success in improving immunization coverage, with an annual growth rate of $2.65 \%$ in FIC, while urban areas have shown little to no improvement. While this may seem anomalous at first, it is well rationalized by the various special challenges that urban areas face. The increasing disparity in urban-rural immunization coverage, coupled with the rapid urbanization of the country has led to slowing growth in immunization cover in India. Through the present analysis, it is evident that without interventions and policies that are urban-sensitive and tailored to the local context, it would be difficult for India to mitigate the impact of COVID-19 or achieve its universal immunization targets.

Supplementary Information The online version contains supplementary material available at https://doi.org/10.1007/s12098-021-03843-0.

Authors' Contributions Conceptualization of the research was done by MP, DD, and MG. Literature review was performed by SK, VT, DD, MG. Collation of studies and data and meta-analysis was done by SK. Evaluation and interpretation was done by SK and VT. Manuscript was written by SK, VT. Policy analysis was performed by SK, VT, DD, RC, MP. Manuscript was reviewed by RC, MP. The research was conducted under the expertise and supervision of MP. MP is the guarantor for this paper.

\section{Declarations}

Ethics Approval As this was a meta-analysis exclusively of published literature, no ethics approval was necessary. 
Conflict of Interest None.

\section{References}

1. Lancet T. The Lancet. India under COVID-19 lockdown. Lancet. 2020;395:1315.

2. Nelson R. COVID-19 disrupts vaccine delivery. Lancet Infect Dis. 2020;20:546.

3. World Health Organization. In: Guiding principles for immunization activities during the COVID-19 pandemic: interim guidance. 2020. Available at: https://apps.who.int/iris/handle/10665/ 331590. Accessed on 29 April 2020.

4. MoHFW (Ministry of Health and Family Welfare), Government of India. In: Guidance Note on Provision of Reproductive, Maternal, Newborn, Child, Adolescent Health Plus Nutrition $(\mathrm{RMNCAH}+\mathrm{N})$ services during \& post COVID-19 Pandemic. 2020. Available at:https://www.mohfw.gov.in/pdf/ GuidanceNoteonProvisionofessentialRMNCAHNServices 24052020. pdf. Accessed on 10 July 2020.

5. Rathi A, Meena GS. Demand and supply side factors affecting utilization of immunization services in an urban village of Delhi. Adv Tech Biol Med. 2017;05:206.

6. International Institute for Population Sciences (IIPS) and ICF. National Family Health Survey (NFHS-4), India. Mumbai: IIPS. 2017.

7. Agarwal S, Sangar K. Need for dedicated focus on urban health within national rural health mission. Indian J Public Health. 2005;49:141-51.

8. Atkinson SJ, Cheyne J. Immunization in urban areas: issues and strategies. Bull World Health Organ. 1994;72:183-94.

9. Prusty SK, Panda B, Chauhan AS, Das JK. Factors affecting immunization coverage in urban slums of Odisha, India: implications on urban health policy. Health Low Resour Settings. 2013;1:e18.

10. Singh S, Sahu D, Agrawal A, Vashi MD. Barriers and opportunities for improving childhood immunization coverage in slums: a qualitative study. Prev Med Rep. 2019;14:100858.

11. Vohra R, Vohra A, Bhardwaj P, Srivastava JP, Gupta P. Reasons for failure of immunization: a cross-sectional study among 12-23-monthold children of Lucknow. India Adv Biomed Res. 2013;2:71.

12. Abedi AJ, Srivastava JP. The effect of vaccination on nutritional status of pre-school children in rural and urban Lucknow. Ind Res. 2012;1:48-50.

13. Athar Ansari M, Khan Z. Routine immunization coverage in underserved children of Aligarh (India): an effort with UNICEF. J Child Health Care. 2010;14:142-50.

14. Assija V, Singh A, Sharma V. Coverage and quality of immunization services in rural Chandigarh. Indian Pediatr. 2012;49:565-7.

15. Babu GR, Singh VV, Nandy S, Jana S, Sathyanarayana TN, Sadhana SM. Supportive supervision and immunization coverage: Evidence from India. Internet J Epidemiol. 2011;9. https://doi. org/10.5580/1437.

16. Barman MP, Nath K, Hazarika J. Factors affecting timeliness of immunization coverage among children of Assam, India: a crosssectional study. J Health Manag. 2015;17:274-84.

17. Bhardwaj N, Goel V. Assessment of immunisation status of infants in an urban area of North Karnataka. Int J Community Med Public Health. 2017;4:2190-2.

18. Chaturvedi R, Sharma RP, Martolia DS, Nigam S, Varma P, Midha T. Evaluation of primary immunization coverage in an industrial city of Uttar Pradesh. Online J Health Allied Sci. 2015;14:2.

19. Singh J, Neki NS. Evaluation of vaccination coverage and Dropout rates among children of age $0-5$ years in slums of Amritsar city. Int J Curr Res Biol Med. 2018;3:16-22.
20. Desai VK, Kapadia SJ, Kumar P, Nirupam S. Study of measles incidence and vaccination coverage in slums of Surat city. Indian J Community Med. 2003;28:10-4.

21. Devasenapathy N, GhoshJerath S, Sharma S, Allen E, Shankar AH, Zodpey S. Determinants of childhood immunisation coverage in urban poor settlements of Delhi, India: a cross-sectional study. BMJ Open. 2016;6:e013015.

22. Fredrick T, Murhekar MV, Jayaraman Y, Ponniah M, Pattabi K, David JK. Target intervention to increase measles vaccination coverage by identifying low-coverage areas using lot quality assurance sampling, Chennai, India, 2012. Indian J Public Health. 2015;59:232-3.

23. Lahiri SK, Ghosh R, Jana PK, Bhattacharya S, Mitra K, Chatterjee A. Evaluation of immunisation coverage of children by lot quality technique in a block of West Bengal. Indian J PrevSoc Med. 2010;41:138-42.

24. Ghosh R, Lahiri SK, Lahiri S, Biswas A, Santra S, Mukherjee P. Coverage evaluation of vitamin A in oil using lot quality technique among the beneficiaries in a block of West Bengal. India IOSR J Dent Med Sci. 2013;10:23-6.

25. Gill K, Devgun P. Impact of socio-demographic factors on age appropriate immunization of infants in slums of Amritsar city (Punjab). India Natl J Community Med. 2015;6:11-5.

26. Gill N, Singh R, Mondal A, Jadhav B. Immunization coverage and its associated factors among children residing in project affected population's resettlement colonies in urban slum of Mumbai, Maharashtra, India. Int J Community Med Public Health. 2016;3:1783-7.

27. Goel N, Abrol A, Pathak R, Sharma M, Gulati S, Swami H. Status of routine immunization in Chandigarh, India. Internet $\mathbf{J}$ Health. 2008;7(1).

28. Gupta PK, Pore P, Patil U. Evaluation of immunization coverage in the rural area of Pune, Maharashtra, using the 30 cluster sampling technique. J Family Med Prim Care. 2013;2:50-4.

29. Gupta P, Prakash D, Srivastava JP. Determinants of immunization coverage in Lucknow district. N Am J Med Sci. 2015;7:36-40.

30. Jain T, Jai Veer S, Manjul B, et al. A cross sectional study on the coverage of immunization in the slums of western Uttar Pradesh. India J ClinDiagn Res. 2010;4:3480-3.

31. Jain M, Taneja G, Amin R, Steinglass R, Favin M. Engaging communities with a simple tool to help increase immunization coverage. Glob Health SciPract. 2015;3:117-25.

32. Jeevaraj J, Narayanan J, Preethi JS, Charumathi B, Dutta R, Jain T. Factors affecting immunization coverage of children in rural area in Tamil Nadu. Indian J Public Health Res Dev. 2019;10:242-6.

33. Johri M, Chandra D, Koné GK, et al. Interventions to increase immunisation coverage among children 12-23 months of age in India through participatory learning and community engagement: pilot study for a cluster randomised trial. BMJ Open. 2015;5:e007972.

34. Joy TM, George S, Paul N, Renjini BA, Rakesh PS, Sreedevi A. Assessment of vaccine coverage and associated factors among children in urban agglomerations of Kochi, Kerala. India J Family Med Prim Care. 2019;8:91-6.

35. Kadri AM, Singh A, Jain S, Mahajan RG, Trivedi A. Study on immunization coverage in urban slums of Ahmedabad city. Health Popul Perspect Issues. 2010;33:50-4.

36. Kameshore N, Joymati O, Singh KB. Coverage evaluation survey of the universal immunization program in North- Eastern India. Ann Int Med Den Res. 2017;3.5.CM1.

37. Karinagannanavar A, Khan W, Raghavendra B, Sameena AR, Goud TG. A study of measles vaccination coverage by lot quality assurance sampling technique and factors related to non-vaccination in bellary district. Indian J Community Health. 2013;25:244-50.

38. Kaushal V. Immunization coverage and nutritional status in under 5 children of urban slums area of karimnagar town. India J Community Med Health Educ. 2018;8:54. 
39. Kulkarni SV, Chavan MK. A Study to assess the immunization coverage in an urban slum of Mumbai by Lot Quality Technique. Int J Med Public Health. 2013;3:21-5.

40. Majumder N, Datta SS, Boratne AV, Majumder N, Basu Majumder C. Determinants of routine and additional vaccine coverage among children (2-5 years) in West Tripura. Indian J Matern Child Health. 2012;14:1-8.

41. Ramesh Masthi NR, Krishna C. Coverage evaluation survey of the pentavalent vaccine using Global Positioning System technology and Google Earth in a rural area near Bangalore. Ann Trop Med Public Health. 2017;10:76-81.

42. Mohan P. Inequities in coverage of preventive child health interventions: the rural drinking water supply program and the universal immunization program in Rajasthan. India Am J Public Health. 2005;95:241-4.

43. Money MK, Mohan P. Measles immunisation coverage in urban slums. Indian J Pediatr. 1999;66:505-9.

44. Murhekar MV, Bitragunta S, Hutin Y, Ckakravarty A, Sharma HJ, Gupte MD. Immunization coverage and immunity to diphtheria and tetanus among children in Hyderabad. India J Infect. 2009;58:191-6.

45. Murhekar MV, Kamaraj P, Kanagasabai K, et al. Coverage of childhood vaccination among children aged 12-23 months, Tamil Nadu, 2015. India Indian J Med Res. 2017;145:377-86.

46. Nath B, Singh JV, Awasthi S, Bhushan V, Kumar V, Singh SK. A study on determinants of immunization coverage among 12-23 months old children in urban slums of Lucknow district. India Indian J Med Sci. 2007;61:598-606.

47. Nath DC, Patowari B. Comparison of survey sampling methods for estimation of vaccination coverage in an urban setup of Assam. India Health. 2015;07:1578-90.

48. Nath L, Kaur P, Tripathi S. Evaluation of the universal immunization program and challenges in coverage of migrant children in Haridwar, Uttarakhand. India Indian J Community Med. 2015;40:239-45.

49. Newtonraj A, Vincent A, Selvaraj K, Manikandan M. Status of coverage of MR vaccination, after supplementary immunization activities in a rural area of South India: a rapid immunization coverage survey. Rural Remote Health. 2019;19:5261.

50. Padda P, Kaur H, Kaur A, Kaur H, Jhajj K. Immunization coverage of optional vaccines. Online J Health Allied Sci. 2012;11:8.

51. Pakhare AP, Pawar R, Lokhande GS, Datta SS. Does seasonal migration for sugarcane harvesting influence routine immunization coverage? A cross-sectional study from rural Maharashtra. Indian J Public Health. 2014;58:116-20.

52. Phukan RK, Barman MP, Mahanta J. Factors associated with immunization coverage of children in Assam, India: over the first year of life. J Trop Pediatr. 2009;55:249-52.

53. Pramanik S, Ghosh A, Nanda RB, de Rouw M, Forth P, Albert $S$. Impact evaluation of a community engagement intervention in improving childhood immunization coverage: a cluster randomized controlled trial in Assam. India BMC Public Health. 2018; 18:534

54. Priyadharshini AJ, Jasmine A. Coverage survey of MeaslesRubella mass vaccination campaign in a rural area in Tamil Nadu. J Family Med Prim Care. 2019;8:1884-8.

55. Punith K, Lalitha K, Suman G, Pradeep BS, Jayanth Kumar K. Evaluation of primary immunization coverage of infants under universal immunization programme in an urban area of Bangalore city using cluster sampling and lot quality assurance sampling techniques. Indian J Community Med. 2008;33:151-5.

56. Rakesh PS, Sheeja A, Subhagan S, Salila K. Closing the immunisation gap: Immunisation coverage evaluation in Kollam corporation Kerala. Kerala Med J. 2015;8:4-8.
57. Francis MR, Nuorti JP, Kompithra RZ, et al. Vaccination coverage and factors associated with routine childhood vaccination uptake in rural Vellore, southern India, 2017. Vaccine. 2019;37:3078-87.

58. Roy R, Chabra P, Saini NK, Kannan AT. Assessment of immunization coverage among infants and pregnant women in Narela using Lot Quality Assurance Technique. Indian J Public Health Res Dev. 2014;5:169-73.

59. Ryman TK, Trakroo A, Ekka JB, Watkins M. Contribution of immunization weeks toward improving coverage, access to services, and completion of recommended childhood vaccinations in Assam. India Vaccine. 2012;30:2551-5.

60. Sachdeva S, Datta U. Hepatitis B immunization coverage evaluation amongst slum children. Indian J Public Health Res Dev. 2012;3:181-4.

61. Sanghvi MM. Study of socio demographic factors influencing vaccination status of children in dared industrial area of Jamnagar. Birth. 2013;1:42-5.

62. Sharma V, Singh A, Sharma V. Provider's and user's perspective about immunization coverage among migratory and non-migratory population in slums and construction sites of Chandigarh. J Urban Health. 2015;92:304-12.

63. Shashidhara YN, Jeyalakshmi K. Vaccination coverage and perceived barriers to immunization as identified by mothers of under five children in rural areas of Udupi district, Karnataka, India: A descriptive survey. J Clin Diagn Res. 2018;12: LC15-8.

64. Singh S, Sahu D, Agrawal A, Vashi MD. Evaluation of vaccination coverage and dropout rates among children aged 12-23 months in the slums of Mumbai, India: preliminary analysis of a cross sectional study. Int J Manag Soc Sci. 2017;5:112-23.

65. Sokhey J, Kim-Farley RJ, Bhargava I. The expanded programme on immunization: a decade of progress in India. Ann Trop Paediatr. 1989;9:24-9.

66. Srirangam Bhaskar V, Kumar MK, Mukerji S, Gupta R. Socio Economic Factors Effecting Immunisation Coverage: Focus Areas. Int J Med Public Health. 2017;7:147-51.

67. Swain BK, Mishra S. Immunization coverage among migrant tribal children in slums of Orissa. Indian Pediatr. 2006;43:1011-3.

68. Takum T, Padung D, Joshua V, Manickam P, Murhekar MV. Programmatic and beneficiary-related factors for low vaccination coverage in Papum Pare district, Arunachal Pradesh. India J Trop Pediatr. 2011;57:251-7.

69. Tatineni A, Vijayaraghavan K, Reddy PS, Narendranath B, Reddy RP. Health metrics improve childhood immunisation coverage in a rural population of Andhra Pradesh. Indian J Public Health. 2009;53:41-3.

70. Todkar SS, Panchal SB. Evaluation of primary vaccination coverage in rural area of Maharashtra, India by 30 cluster sampling technique. Indian J Public Health Res Dev. 2016;7:147-52.

71. Trivedi R, Singh S, Adhikari P, Jatav DP. Coverage evaluation of primary immunization and the associated determinants in an urban slum of Rewa. Indian J Community Health. 2014;26:37-40.

72. Undavalli VK, Narni H, Muthe A, Ponnaganti SC, Jonnalagadda RK. Application of Lot Quality Technique for immunization coverage and quality assessment. Indian J Public Health Res Dev. 2017;8:46-50.

73. Varma GR, Kusuma YS. Immunization coverage in tribal and rural areas of Visakhapatnam district of Andhra Pradesh. India J Public Health. 2008;16:389-97.

74. Kumari SV, Prabha MS. A study on immunization status among under five children in urban area of Kurnool, Andhra Pradesh. J Evid Based Med Healthc. 2017;4:4443-7.

75. Ministry of Health and Family Welfare (India), ORG Centre for Social Research (ORG CSR), United Nations Children's Fund (UNICEF). India Cover Eval Surv. 2009-2010. 2011. 
76. International Institute for Population Sciences (IIPS) and Macro International. National Family Health Survey (NFHS-3), 2005-06: India. Volume I. Mumbai: IIPS. 2007.

77. International Institute for population. Sciences (IIPS). District Level Household Survey (DLHS-2), 2002-04: India. Mumbai: IIPS. 2006.

78. International Institute for Population Sciences (IIPS). District Level Household and Facility Survey (DLHS-3), 2007-08: India. Mumbai: IIPS. 2010.

79. Ministry of Women and Child Development (MoWCD), Government of India.In:Rapid Survey on Children, Natl Rep, 2013-14. 2014. Available at: https://wcd.nic.in/sites/default/files/RSOC\% 20National\%20Report\%202013-14\%20Final.pdf. Accessed on 27 Mar 2020.

80. Basu RN. Smallpox eradication: lessons learnt from a success story. Natl Med J India. 2006;19:33-6.

81. Sharma S. Immunization coverage in India. Delhi: Institute of Economic Growth, University of Delhi. 2007. Available at: http:// iegindia.org/upload/publication/Workpap/wp283.pdf. Accessed on 2 Oct 2019

82. Lahariya C. A brief history of vaccines \& vaccination in India. Indian J Med Res. 2014;139:491-511.

83. Awoh AB, Plugge E. Immunisation coverage in rural-urban migrant children in low and middle-income countries (LMICs): a systematic review and meta-analysis. J Epidemiol Community Health. 2016;70:305-11.

84. Gatchell M, Thind A, Hagigi F. Informing state-level health policy in India: The case of childhood immunizations in Maharashtra and Bihar. Acta Paediatr. 2008;97:124-6.

85. Chakrabarty A. Ranabir Samaddar (Ed.), Borders of an epidemic: COVID-19 and migrant workers. Int J Com Soc Dev. 2020;2:286-7.

86. UNICEF.In:The impact of COVID-19 on routine vaccinations. 2020. Available at: https://www.unicef.org/eap/stories/ impact-covid-19-routine-vaccinations. Accessed on 3 June 2020.

87. Agarwal S, Bhanot A, Goindi G. Understanding and addressing childhood immunization coverage in urban slums. Indian Pediatr. 2005;42:653-63.
88. Kumar S, Kumar S, Gupta B. Urban health: needs urgent attention. Indian J Public Health. 2018;62:214-7.

89. MoSPI (Ministry of Statistics and Program Implementation), Government of India. In:NSS 69th Round, Urban Slums in India 2012. 2014. Available at: http://mospi.nic.in/sites/default/files/ publication_reports/nss_report_561_19dec14.pdf. Accessed on 4 Aug 2020.

90. Nolan LB, Bloom DE, Subbaraman R. Legal Status and Deprivation in Urban Slums over Two Decades. Econ Polit Wkly. 2018;53:47-55.

91. Subbaraman R, O'brien J, Shitole T, et al. Off the map: the health and social implications of being a non-notified slum in India. Environ Urban. 2012;24:643-63.

92. MoHFW (Ministry of Health and Family Welfare), Government of India. In: Rural Health Statistics. 2019. Available at: https://main. mohfw.gov.in/sites/default/files/Final\%20RHS\%202018-19_0.pdf. Accessed on 4 Aug 2020.

93. Pradhan N, Ryman TK, Varkey S, et al. Expanding and improving urban outreach immunization in Patna. India Trop Med Int Health. 2012;17:292-9.

94. Dasgupta P, Bhattacherjee S, Mukherjee A, Dasgupta S. Vaccine hesitancy for childhood vaccinations in slum areas of Siliguri. India Indian J Public Health. 2018;62:253-8.

95. Favin M, Steinglass R, Fields R, Banerjee K, Sawhney M. Why children are not vaccinated: a review of the grey literature. Int Health. 2012;4:229-38.

96. Krishnamoorthy Y, Kannusamy S, Sarveswaran G, Majella MG, Sarkar S, Narayanan V. Factors related to vaccine hesitancy during the implementation of measles-rubella campaign 2017 in rural Puducherry-a mixed-method study. J Family Med Prim Care. 2019;8:3962-70.

97. Lahariya C, Bhardwaj P. Adult vaccination in India: status and the way forward. Hum VaccinImmunother. 2020;16:1508-10.

98. Vithayathil T, Singh G. Spaces of discrimination: residential segregation in Indian cities. Econ Polit Wkly. 2012;47:60-6.

Publisher's Note Springer Nature remains neutral with regard to jurisdictional claims in published maps and institutional affiliations. 